\title{
Briga de galos no Maranhão: didáticas através de apropriações de textos de antropologia
}

\author{
LUIZ A. COUCEIRO \\ UNIVERSIDADE FEDERAL DO MARANHÃO (UFMA), SÃO LUÍS/MARANHẼO, BRASIL \\ HTTPS://ORCID.ORG/OOOO-0003-I28I-8048
}

Entre julho de 2014 e janeiro de 2015, lecionei a disciplina Laboratório de Ensino em Ciências Sociais (doravante LECS), da qual a ementa previa levar os(as) alunos(as) a observar, relatar e analisar relações sociais a partir do universo escolar ${ }^{1}$. No primeiro dia de LECS, apresentei-me, dizendo que era professor de antropologia na Universidade Federal do Maranhão (UFMA), no campus de São Luís e que programara as aulas para que trechos dos textos selecionados fossem lidos pelos(as) alunos(as), em voz alta e revezamento. LECS fazia parte das atividades do Plano Nacional de Formação de Professores da Educação Básica (Parfor), em Codó - município localizado no leste do Maranhão, a cerca de 300 km da capital, São Luís. A UFMA aderiu ao Parfor em 2009, ano da criação do programa, oferecendo, dentre outros, curso de licenciatura em Ciências Sociais, em regime de colaboração entre a Coordenação de Aperfeiçoamento de Pessoal de Nível Superior (Capes) e os governos estaduais e municipais, além do Distrito Federal, através de instituições de ensino superior.

Os(as) alunos(as) envolvidos(as) na disciplina residiam não só em Codó, mas também em municípios próximos, como Caxias, Peritoró e São Mateus do Norte, sendo todos(as) professores(as) em

1 Esse artigo contou com auxílio da Capes para a realização das aulas no Parfor. Quero agradecer a Gamaliel Carreiro, então coordenador do Programa de Formação de Professores para Educação Básica (Profebpar) na UFMA, pelo convite para lecionar LECS em Codó (MA), assim como pela confiança dos alunos no trabalho realizado.

A redação da primeira versão ocorreu no período do pós-doutorado, realizado entre agosto de 2019 e agosto de 2020 no Fernand Braudel Center (FBC), na State University of New York (SUNY) - Binghamton University, com bolsa Fapema de pós-doutorado no exterior. No FBC, contei com excelente ambiente de trocas as mais diversas e o suporte dos professores Richard Lee e Dale Tomich e da logística burocrática de Amy Keough e Kelly Pueschel que, junto com Rejane Valvano, Roberto Ortiz e Odika (Odie) Santiago, proporcionaram inesquecíveis momentos de amizade para irreverentes e importantes reflexões. Ainda na SUNY, fundamentalmente depois da eclosão da pandemia de covid-19, recebi amigável, eficiente e essenciais suportes do professor Joshua Price e de Joseph (Joe) Citriniti, no Departamento de Sociologia.

Os(as) pareceristas e revisores(as) da Campos muito me ajudaram a amadurecer os argumentos apresentados, com preciosas dicas que busquei aproveitar, sem descaracterizar a ideia e o estilo do artigo. Deixo aqui meu muito obrigado, assim como às editoras desse dossiê especial, sempre muito atentas e profissionais no diálogo para o fechamento da versão final para publicação. Todas as ideias presentes nesse artigo são de minha inteira responsabilidade. 
atividade. Eram o público alvo do Parfor, isto é, pessoas buscando obter formação em licenciatura na área em que já atuavam ou numa segunda área na qual tinham interesse em trabalhar. Eles(as) integravam os 17.427 alunos(as) que em 2014 faziam parte do programa, na região Nordeste do Brasil que, junto com a Norte, foi uma das que mais contou com municípios interessados².

Entre um e outro texto, minha ideia era explicar e contextualizar, em linhas gerais, o que estava sendo dito, filtrando a linguagem específica das Ciências Sociais para abrir possibilidades de diálogo com a turma. Assim, perceberia de que maneira os(as) alunos(as)s estariam sendo afetados(as) pelas ideias que começava a lhes apresentar. Contudo, para minha surpresa, o impacto maior foi o fato de eu ter dito ser professor de antropologia!

Quando indagado se isso era verdade, pensei que os(as) alunos(as) talvez me questionassem sobre não ser professor de sociologia e sim de antropologia e, em seguida, quisessem saber mais claramente as diferenças e semelhanças entre ambos os campos de conhecimento. Não seria algo incomum nas minhas experiências docentes, o que me levou a incorporar, logo no início de todas as disciplinas, um breve panorama das especificidades da sociologia, antropologia e ciência política, que compõem os cursos de graduação em Ciências Sociais. Mas a surpresa veio de outra direção!

Os(as) alunos(as)s pediram que eu fizesse um "resumão de antropologia", alegando que "não haviam entendido" o que se propunha nessa disciplina. Perguntei o que estavam querendo dizer com isso, se gostariam que eu explicasse o quê e como, em linhas gerais, os(as) antropólogos(as) estudam, quais seriam as temáticas abordadas, algumas das principais linhas teóricas e seus conceitos consagrados. Responderam, sem maiores constrangimentos, que "estariam no lucro com qualquer coisa que eu fizesse, porque não sabiam nem ao menos o que poderia ser antropologia como disciplina”. Meio constrangido, confesso, resolvi aceitar o que encarei como sendo um desafio. Afinal de contas, também estava curioso com o que a inusitada situação poderia revelar na relação de ensino e aprendizagem.

Desde o início, não abri espaço para indagações sobre os motivos pelos quais "não haviam tido", segundo suas palavras, "uma experiência feliz com antropologia”, o que foi rapidamente compreendido pela turma. Minha preocupação era não polemizar sobre as versões acerca do desempenho do(a) colega que havia lecionado antropologia, nem sobre seus métodos. Penso que são inúmeros os fatores que levam uma disciplina a ser avaliada como bem ou malsucedida, além das possibilidades de construção de empatia e antipatia entre os(as) docentes e alunos(as).

Como estratégia inicial, vislumbrei construir com os(as) alunos(as) uma narrativa que os(as) fizesse observar como tudo o que eu estivesse explicando, ou grande parte, lhes seria útil na compreensão de situações concretas de suas vidas e nos sentidos que as pessoas ao seu redor conferem à sua existência. Mais que isso, avaliei que pudesse ser do interesse dos(as) alunos(as), no tempo que tínhamos disponível (parte de uma manhã e de uma tarde), o entendimento dos modos pelos quais construímos tais sentidos.

O que busquei, ao fim e ao cabo, foi que houvesse uso dos textos de antropologia, por parte dos(as) alunos(as), valorizando as conexões que faziam entre suas experiências e as dos(as) autores(as), cabendo-me efetuar as devidas mediações sobre os diferentes contextos. Recentemente, desenvolvi o 
conceito de etnografia hiper-realista para tratar dos significados desse tipo de experiência (Couceiro, 2020), sistematizando reflexões apresentadas inicialmente em artigo anterior (Couceiro, 2017). Aqui, busco aprofundar pontos que não havia sido possível tratar nos precedentes, em função da minha intenção de não escapar do foco de cada texto.

Nessa linha, compreendo os argumentos produzidos pelos(as) antropólogos(as) não como dados, mas sim como construções a partir de escolhas conceituais metodológicas e epistemológicas, tanto presentes em clássicos (Singer \& Street, 1972; Firth, 1957; Thornton, 1985; Evans-Pritchard, 1931; Stocking Jr., 1983), como em autores(as) contemporâneos(as) (Ortner, 2007; Amit, 2000; Hume \& Mulcock, 2004), tratando o campo de investigação como algo aberto, em construção e que não se encontra pronto à espera do(a) pesquisador(a). Além disso, considero importante avaliar em que termos os(as) interlocutores(as) compreendem seu contato com os(as) antropólogos(as) e em que medida fazem uso de conceitos e perspectivas da disciplina, no processo de construção de sentido às suas vivências (Foote Whyte, 2005; Crapanzano, 1980; Mintz, 1984; Abu-Lughod, 1986).

Por fim, nesse texto encontram-se reflexões sobre os modos pelos quais as conversas são construídas em campo e seu papel na etnografia produzida. No caso apresentado, em sala de aula, entre o professor que também é pesquisador e os(as) interlocutores(as) que também são alunos(as), na medida dos apontamentos de Rapport (1997), sobre a cultura ser parte de exercícios de construção de significação de experiências pessoais e coletivas, incluindo as condições sociais que possibilitaram as conversas nos ambientes da pesquisa.

Uma vez aceito o desafio do "resumão", comecei, então, a explicar as assim chamadas "escolas da antropologia", fazendo uma breve narrativa dos motivos pelos quais as primeiras gerações de antropó$\operatorname{logos}$ (as) profissionais nos EUA, na Inglaterra e França analisavam quais tipos de materiais de investigação, tecendo comentários acerca das características deles. Em seguida, passei a ler trechos de textos de autores(as) considerados(as) clássicos(as) e que tinha disponíveis em meu computador.

Como estratégia pedagógica, abordei processos de construção de classificação social através de discussões entre natureza e cultura, costurando os(as) vários(as) autores(as) exemplares de tipos de antropologia. Quando cheguei ao texto "Um jogo absorvente", de Clifford Geertz (2000), os(as) alunos(as) ficaram indignados(as) e, sem cerimônia, fazendo piadas, riram de suas interpretações da briga de galos. Pediram que eu lesse com calma a descrição do evento narrado pelo autor. Naquele momento, não havia entendido o porquê.

Depois da pausa para o almoço, descobri que os(as) alunos(as) eram, em vários níveis, entendidos(as) de briga de galos. Assim, interpretaram os trechos que li de Franz Boas (2004a, 2004b), Bronislaw Malinowski (1935, 1984), Arnold Radcliffe-Brown (1922, 1978), Claude Lévi-Strauss (1997) e Edmund Leach (1996) como parte de narrativas desse universo, questionando o que inicialmente captaram das análises de Geertz. A partir das narrativas apresentadas, quis saber dos(as) alunos(as) sobre o perfil dos(as) participantes, dinheiro envolvido, as rivalidades, fofocas, questões de honra, buscando perceber a importância disso nas suas vidas e nos cenários locais. Muito embora minha etnografia leve em conta aspectos do perfil de trabalho produzido por Geertz no artigo sobre briga de galos em Bali, 
não entrei nos detalhes de suas estratégias argumentativas e estilo de escrita, detalhadamente analisadas por Crapanzano (1986), na medida em que não era meu foco ${ }^{3}$.

Tendo como base as experiências dos(as) alunos(as) e suas leituras pragmáticas dos textos, busquei compreender quais os sentidos de tal conteúdo para eles(as) e, principalmente, dos argumentos de Geertz, no referido artigo. Como os(as) alunos(as) leram as evidências etnográficas desse autor, segundo suas perspectivas? Qual foi o lugar das experiências deles(as) nas dinâmicas de ensino-aprendizagem de antropologia? São essas as questões norteadoras deste artigo, partindo da investigação das interpretações coletivas daqueles textos de antropologia, de como os(as) alunos(as) conferiram entendimento aos argumentos e às pesquisas dos(as) autores(as), seus mecanismos de apropriação, através de seus códigos de significação e de conduta moral.

\section{"Geertz não conhece briga de galos ou é apenas um muquirana?"}

No início dos anos 1970, Clifford Geertz, antropólogo estadunidense, sistematizou artigos em um livro sobre o que chamou de teoria interpretativa da cultura, ou antropologia hermenêutica, aplicada aos dados de suas pesquisas no Marrocos e na Indonésia (Geertz, 2000). Geertz pôde, depois de dois anos de trabalho de campo em Bali, lecionar na Universidade de Chicago por dez anos e amadurecer suas ideias, bem como formular conceitos, estudando autores que ainda não havia tido oportunidade de ler, na medida em que teria feito um curso de graduação com quase nenhum acesso às ciências sociais.

Em parte, isso teria ocorrido também em seu doutorado, posto que participara de um programa de pós-graduação em Relações Sociais, em Harvard, que não era concentrado em sociologia e nem em antropologia (Hirsch \& Wright, 1993; Handler, 1991; Geertz, 1995). A perspectiva desenvolvida por Geertz em alguns capítulos do livro manteve a importância da construção social dos sentidos das palavras, perpassando temas principais da antropologia (Fonseca, 2008), assim como fizeram Malinowski e Leach, contudo, enfatizando os contextos nos quais elas foram ditas e os significados das coisas não ditas, como gesticulações e expressões faciais (Swidler, 1996). O autor conformou uma estratégia argumentativa para avaliar qual fato vivido em campo, pelo pesquisador, poderia ser elegido como algo importante para o desenvolvimento da etnografia - algo já realizado, em diferente perspectiva teórica, por Gluckman (1987), vale lembrar.

Um dos capítulos trata de uma briga de galos (Geertz, 2000) e de seus desdobramentos como chave de entendimento de valores morais os mais diversos na aldeia em que Geertz e sua esposa pesquisavam, com pretensões de alargar o escopo para toda Bali. O evento, clandestino, mas tolerável pelas autoridades locais, visava a angariar fundos para a construção de uma escola. Geertz explica no texto o quanto a briga de galos mexia com o imaginário das autoridades, tendo passado por momentos em que era uma atividade lícita, noutros ilícita e de obscuridade, na prática. Suas investigações indicaram que as

3 Agradeço a um(a) dos(as) pareceristas do artigo por indicar esse tipo de esclarecimento, já no corpo do texto e no início do artigo. 
autoridades tinham medo de um suposto descontrole moral provocado pela excitação do ambiente de apostas e bebedeiras, típicas preocupações policiais com a manutenção do que entendem como ordem.

Os policiais teriam chegado repentinamente, interrompendo o evento, pondo todos pra correr, o que deu trabalho ao casal Geertz, que optou pelo sebo nas canelas ao risco da cana dura. No dia seguinte, na aldeia, ao acordarem, algo novo havia ocorrido. Outrora pouco afáveis, seus habitantes passaram a falar com os Geertz, fazendo piadas de sua participação na intrépida e bem-sucedida fuga das garras dos meganhas. A partir daí, Clifford Geertz discorre sobre os significados dos mais variados aspectos da briga de galos em Bali, inclusive os paramentos, o quanto de dinheiro era apostado, os comportamentos dos(as) torcedores(as) e empresários(as), donos(as) dos animais.

Assim, terminava a primeira manhã de LECS, cabendo no início da tarde retomar as poucas discussões de antropologia com a turma, bem como fazer as primeiras conexões com os autores e as temáticas relativas a ensino e aprendizagem, além das relações sociais nos espaços escolares e familiares na sua mútua influência na vida escolar. Esse, afinal, seria o objetivo inicial programado para ser lecionado.

Já havia observado que os semblantes dos(as) estudantes durante as explicações sobre o tipo de antropologia proposto e realizado por Geertz havia mudado. Algumas risadas haviam sido dadas, principalmente nos momentos em que eu lhes falava dos aspectos da briga de galos levantados por Geertz, antes e depois da batida policial. No início da tarde, bem-humorados(as), os(as) alunos(as) pediram a palavra logo no início da aula, colocando algumas interrogações sobre questões que lhes estavam angustiando. A primeira era "se Geertz seria muquirana", ou seja, em linguagem popular, um sovina.

Um tanto quanto perturbado, confesso, indaguei o que os(as) teria levado a essa pergunta - aliás, segundo a turma, "muito debatida durante o seu almoço". Afirmaram que "o autor", ao menos, não necessariamente o casal, "deveria ter apostado dinheiro alto, por ser gringo", e, ao que a turma avaliava, "pelo dólar provavelmente valer bem mais do que a moeda local". Para os(as) estudantes, tratava-se de uma operação simples: perguntar sobre as tabelas de apostas, obter informações sobre o desempenho esperado pelos galos, escolher um em cada briga e colocar dinheiro nas mãos do(a) organizador(a).

"Ao não fazer isso", continuaram, "Geertz demonstrava recusa em participar da arrecadação de dinheiro pra escola". A turma reagiu mal a isso, ao que seria uma ofensa considerada universal, porque em todos os lugares seria algo notavelmente desagradável e sem sentido um professor mostrar pouca sensibilidade à reconstrução de uma escola. Nesse quesito, um aluno ainda afirmou que "teria sido um gesto nobre de Geertz apostar sem necessariamente saber qual dos galos iria ganhar, mas, apenas, para demonstrar empatia pela nobreza da causa”.

Comecei, então, a perceber que a turma tinha conhecimento mais apurado sobre briga de galos e de que esse tema poderia ser aproveitado no estreitamento de relações entre nós. Afinal, teríamos poucos finais de semana de convivência. Além disso, depois de diversas leituras do famoso artigo de Geertz, eu nunca havia prestado atenção que o motivo do evento-chave por ele analisado fora para angariar fundos à reforma de uma escola local. Interpretei isso como uma demonstração de interesse dos(as) alunos(as) pela estratégia pedagógica adotada e, em alguma medida, pelo modo como eu havia explicado o que seria antropologia, independente do(a) autor(a) a ser abordado. Decidi que iria explo- 
rar tal cenário, podendo produzir junto à turma conexões com a literatura de sociologia e antropologia em educação.

Desta feita, perguntei aos/às alunos(as) qual seria o papel da briga de galos em suas vidas, avaliando que ir direto ao ponto significava colocar em risco a empatia inicial com a turma, na medida em que poderia ofender alguém pelo fato de estar sendo diretivo. Valeu o risco, posto que todos(as) os(as) alunos(as) soltaram risadas e me disseram, quase simultaneamente, que "há várias gerações conviviam com brigas de galos”. Não eram "apostadores(as), nem treinadores(as), criadores(as) ou donos(as) de galos de briga”, termos usados por eles(as), mas conheciam bem esse universo.

Perguntei, assim, quem seriam esses personagens nas tramas daquelas brigas, ao que disseram que um era "dono(a) do galo porque o teria comprado". Essa pessoa "nem sempre seria a criadora do animal", mas apenas um(a) “investidor(a)", "pagando o(a) criador(a)" para que pudesse alimentá-lo adequadamente e prepará-lo para "ser um vencedor". Na esperança de ter um futuro campeão em mãos, o(a) dono(a) ainda proveria o pagamento de um "especialista", "o treinador", para colocar o galo em ponto de briga. Tal processo somente seria possível sob a responsabilidade de um treinador, com competência reconhecida entre os participantes desse universo, um currículo invejável de galos campeões, validado nas histórias contadas na região.

Um aluno, nesse momento, lembrou que Malinowski dizia, segundo minha explicação, que não seria mágico quem quisesse, mas somente quem a opinião pública considerasse. $\mathrm{O}$ treinador era peça-chave, na medida em que comprar um galo e alimentá-lo não fariam dele um destaque nas brigas. Ou seja, era parte do investimento pagar pelos serviços do treinador. Este seria, para outra aluna, uma espécie de mágico, porque ninguém sabia como ele fazia para um galo ser bom de briga, mas todos(as) viam que trabalhava duro, conversando com o galo, dando-lhe estímulos, por exemplo, com um pedaço de pau simulando um adversário ciscando na sua frente e o ameaçando. Segundo sua avaliação, tais métodos funcionavam e fazer de um galo um campeão seria como construir uma embarcação de sucesso nas trocas do Kula.

O ponto seguinte, levantado por outros dois alunos, foi a relação da briga de galos com demais aspectos da vida vivida nas localidades implicadas, o que estaria ligado ao exercício reflexivo realizado por Geertz. Para esses estudantes, os galos seriam uma parte dos "princípios morais do treinador" e não do(a) dono(a). Este, argumentaram os dois alunos, com sinais de concordância dos(as) demais, seria apenas um investidor, sem demonstrar interesse em ter alguma conexão afetiva com galo. Assim, ele estaria fora da relação entre natureza e cultura, apontada por Lévi-Strauss, na medida em que não “pensaria sua existência através do galo”, mas tão somente pelo lucro que este lhe pudesse gerar, segundo observou outra aluna.

Já o criador teria uma experiência mais envolvente com os galos, porque o objetivo seria condicioná-los para brigar, de preferência, em boa parte de sua vida. "Deveriam ser criados para aguentar os treinamentos", encarados como desafios, se superando, "demostrando boa saúde e força de vontade", valores passados pela convivência com o criador e até mesmo sua família. Um(a) dos(as) alunos(as) argumentou ser o "ambiente familiar" fundamental na construção do "caráter do galo", dizendo que certos galos seriam de "boa índole" ao pararem de golpear o adversário. Isso porque "perceberiam" que 
o teriam superado, vendo que o oponente não apresentava mais forças para continuar a lutar. Outros seriam "mau-caráter", posto que não paravam de brigar enquanto não "ferissem mortalmente" o adversário. Todos os(as) alunos(as) afirmaram que jamais teriam conhecido um galo que não se comportasse igual ao criador. Por morarem juntos, "a convivência afetaria o animal", ao contrário do treinador, que frequentaria a casa do criador, na medida em que chegava, fazia os exercícios com o galo e, ao final da jornada, voltava para sua residência. Para uma aluna, alguns treinadores até atenuavam as influências dos criadores, mas não as anulavam.

Lembrando minhas observações sobre Radcliffe-Brown, assim como de minha leitura de trechos do seu livro (Radcliffe-Brown, 1922), a mesma aluna avaliou que "os galos seriam parte da natureza local" e ajudavam na classificação de aspectos centrais da vida moral das pessoas, em seus diferentes níveis de envolvimento com as brigas de galos. Através desses animais e desse complexo de interações que compunham o universo das brigas, observadas para além de um simples jogo, "as pessoas falavam de suas vidas, de suas relações com outras pessoas".

Além do mais, a aluna disse que "eram uma oportunidade para resolver querelas". Na sequência, narrou um caso curioso e popular na região, de uma disputa de terras entre famílias importantes, ou seja, consideradas ricas, levada para uma aposta de rinhas de galos. Durante meses ambas as famílias viraram donas de galos, viabilizando sua preparação, na medida em que haviam reconhecido desacordo sobre os limites de uma cerca que separava as suas propriedades.

A ideia, segundo outro aluno, não seria apenas conseguir mais um pedaço de terra, o que não faria tanta diferença para nenhuma das duas famílias, posto já ricas, segundo seu entendimento. O que estaria em jogo seria a honra da palavra relativa à medida exata de cada propriedade, não registrada em cartório ou com documentos juridicamente duvidosos. Assim, ambas as famílias mandaram trazer comida e treinadores de outros estados, pedindo indicações sobre os que fossem considerados os mais entendidos do assunto nos municípios vizinhos.

A briga foi marcada em lugar de comum acordo entre os dois patriarcas, assim como quem seria o juiz. A aluna que se lembrou desse acontecimento afirmou que o juiz não teria muito trabalho, haja vista que as famílias haviam contratado treinadores para produzir "galos transformados em máquinas de matar". Dito e feito. Na briga, um galo matou o outro, o resultado foi respeitado, sacramentado em cartório com o reconhecimento das terras na medida do desejo da família vencedora.

Depois desse exemplo, perguntei se havia pessoas que viviam das brigas de galos, de seus papéis nessas redes de preparações. A turma produziu uma risada coletiva de espanto, na minha interpretação, pois para ela seria algo óbvio, embora não para mim. Na região, ganhar dinheiro dessa maneira, sendo dono(a), criador(a) treinador(a), organizador(a) das brigas ou mesmo um(a) apostador(a) de sucesso, era entendido como algo legítimo, até certo ponto admirável. Os argumentos giravam ao redor da expertise que essas pessoas deveriam ter para garantir o retorno financeiro, lidando, em alguns momentos, com derrotas.

Vale dizer que há um conflito de entendimentos na lei, no Brasil, sobre ser ou não a briga de galos um evento criminoso. Segundo a Constituição Federal de 1988, seria um crime de proteção aos animais (inserido no art. 225, §1º Cap. VI), também amparado pelo art. 32 da Lei de Crimes Ambientais. 
Contudo, segundo a Emenda Constitucional no 96, seria permitida se entendida como prática desportiva com a utilização de animais. Um aluno, de certa maneira sem graça, em tom de voz mais baixo, lembrou que, para as autoridades, assim como no texto de Geertz, a briga de galos era contra a lei. Ou seja, não bastava, para o estudante, ser um crime previsto por escrito, mas sim ser, de fato, fiscalizado, se fosse entendido como merecedor de fiscalização, de acordo com o grau do dano causado à sociedade.

Assim, disse outro aluno, haveria duas maneiras de lidar com a situação, por parte dos mais envolvidos: cooptar autoridades ou conseguir que os eventos não fossem descobertos. Nada disso era visto como corrupção, por ele, na medida em que algumas das autoridades locais, leia-se policiais e, em segundo lugar, fiscais do Ibama (Instituto Brasileiro do Meio Ambiente e dos Recursos Naturais Renováveis), seriam conhecedores desse costume e de sua importância na região. Além disso, continuou uma discente, era de entendimento geral que reprimir brigas de galos seria algo irrelevante dentre as prioridades, tais como ir atrás de ladrões de cargas e ônibus, assassinos foragidos, combater roubo de madeira e arbitrar disputas de terras. Era sabido, disse outro aluno, que o contingente de policiais e fiscais não era suficiente para esses serviços, "imagine para algo tão inofensivo e fundamental”, em sua avaliação, "que seria reprimir briga de galos!".

Voltando ao texto de Boas (2004a), esse estudante avaliava que os usos dos galos para as brigas seriam "algo típico da cultura local, há décadas", fazendo parte de conversas entre familiares e amigos. Não caracterizaria algo antiecológico porque seriam pouquíssimos os galos usados para as brigas, em razão do número de animais disponíveis na região. Mesmo assim, segundo seu olhar, raras eram as situações de galos que morriam em conflito ou ficavam aleijados. Na maioria dos casos, continuava suas ponderações, recuperavam-se das contusões ao serem tratados pelos mesmos criadores. Nesse momento, uma aluna afirmou terem esses galos mais sorte na vida que muita gente na região, porque algumas pessoas doentes ou idosas eram abandonadas frequentemente à sorte de maus-tratos, tendo morte indigna e rápida - que poderia, de certa forma, ter sido evitada.

\section{O sumiço da escola}

No momento em que retornamos ao texto de Geertz, uma aluna perguntou: "mas, afinal, por que a escola some do texto, uma vez que é uma coisa fundamental na vida de qualquer lugar?". Lembrei de certa provocação de Caplan (2003) à produção de Geertz no início dos anos 1970. Caplan, ao escrever um balanço acerca das preocupações éticas e morais de antropólogos nos EUA e na Inglaterra, afirmou, claramente se referindo a Geertz, que, à época, enquanto alguns preferiam investir numa antropologia idealizada através de teorias abstratas da cultura e da comunicação, outros buscavam alicerces mais empíricos para refletir sobre seus compromissos profissionais.

A autora recorda as contribuições de Talal Asad (Caplan, 2003:7-8), quando este questionou o jargão de ser a antropologia uma área de saber conivente com políticas de dominação dos impérios coloniais. Asad propõe uma via de mão dupla para compreender essas complexas, não menos sofridas e desiguais, relações entre os antropólogos oriundos de centros colonizadores e seus/suas interlocutores(as) durante o trabalho de campo. Asad pergunta: até que ponto antropólogos(as) profissionais 
viam de fato essas pessoas e os(as) moradores(as) das áreas pesquisadas como meros(as) informantes? (Caplan, 2003:9). A autora lembra, ainda, que Dell Hymes, no mesmo período de Asad, organizou um livro que defendia o posicionamento político mais radical dos(as) antropólogos(as), ao reivindicarem o que entendiam ser os interesses dos "seus" / "suas" interlocutores(as), a partir de uma posição de prestígio na academia, algo também enfatizado por George Appell.

Nessa mesma linha de interrogação, alguns anos mais tarde, Mintz (1984) escreveu sobre sua relação com Taso, interlocutor fundamental para seu trabalho de campo em Porto Rico, e os seus impactos na trajetória de cada um. Na abordagem de Mintz, percebe-se o espaço para reflexões profundas sobre o perfil de Taso, aspectos centrais de sua vida que influenciaram o grau de afinidade com os propósitos das investigações sobre a dinâmica de vida dos trabalhadores nos canaviais. Ao fim, lembrei de artigo de Fabian (1971) em que concordava com Asad e observava a necessidade de não se entender "a" história da antropologia, indo além de seus limites de outrora, mas sim avaliar os impactos das investigações para as populações pesquisadas, bem como a relação possível entre estas e os(as) pesquisadores(as). Também valeria pensar o oposto: quais foram os motivos que impediram o estabelecimento de certos perfis de relação entre o pesquisador(a), seus/suas interlocutores(as) e demais agentes da região pesquisada.

Perguntei aos alunos se Geertz estivesse na região de Peritoró, pesquisando as brigas de galos, deveria denunciar os(as) participantes como criminosos(as). Ou se, por outro lado, Geertz deveria estudar a briga de galos como parte do costume, da cultura, no sentido de Boas (2004b), digamos assim, buscando entender como os(as) seus/suas participantes lhe conferiam significado, enfatizando menos os jogos de linguagens. Os(as) alunos(as) não titubearam e afirmaram, quase em uníssono, que jamais deveria denunciar ninguém!

Lembraram o argumento sobre a briga de galos não afetar sensivelmente elementos da natureza, do meio ambiente e servir para confraternizações. Além disso, tal como os colares e braceletes no Kula, conforme comparou uma aluna lembrando o trabalho de Malinowski (1984), a atividade fazia o dinheiro circular em um lugar onde, para ela, havia sua pouca disponibilidade para maior parcela da população.

Percebi, dessa maneira, como a briga de galos saltou do texto de Geertz para o recente interesse da turma pela antropologia, a partir de uma leitura mais livre e ligada às situações que vivenciavam. Ao me preocupar em não fazer leituras monocórdias de trechos dos textos dos autores que resumi nas minhas narrativas, dentro dos critérios já explicados, propositalmente abri espaços para interlocução com os(as) alunos(as). Sabia da curiosidade deles(as) pela antropologia e desconfiava até que ponto achariam interessante esse campo de saber.

O caminho que segui em poucas horas, nas quais tinha o desafio de explicar linhas básicas do que seria antropologia, que tipo de conhecimento e como seus/suas autores(as) o produziam, foi possível por não desprezar os primeiros sentidos que os(as) alunos(as) estabeleciam entre o que eu lhes narrava e suas experiências de vida. Tão importante quanto ensinar era fazê-lo deixando claro que isso só possui

4 Posteriormente, constatei que Caplan (2003) também faz uso desse artigo em sua argumentação. 
sentido na medida em que a vida dos(as) alunos(as) importa, tornando-se significativa no processo de ensino e aprendizagem.

Os(as) alunos(as), ao longo das explicaçóes, foram tomando conta das informações naquilo que entendiam como lhes sendo útil para a compreensão de situações por eles(as) vivenciadas. O conteúdo foi ganhando sentido na medida das conexões com suas experiências, com os(as) estudantes se apoderando dos acontecimentos em sala de aula como um momento para questionamentos, experimentando-a como um espaço em que não serão moralmente julgados(as). Cabe, sem dúvida, ao(à) professor(a) encorajar que façam o exercício de falar o que entenderam do texto, dos(as) autores(as), nos termos que lhes vierem à mente e não os colocar em situação de desconforto. Ao contrário, trata-se de um momento pedagógico estratégico para cativar interesse dos(as) alunos(as), demonstrando que podem e devem expressar descentramentos afetivos que os(as) autores(as) lhes possam estar despertando.

Aquilo que seria mais uma aula, um laboratório de sociologia do ensino e da educação, transformou-se, com todos os improvisos relatados, numa oportunidade de realizar um experimento etnográfico em ensino e aprendizagem em antropologia. Aqui, o entendimento de etnografia reside com mais peso na perspectiva de experimentar, com a turma, ressignificações de situações da vida particular e coletiva, conferindo-lhes novas perspectivas ou mesmo produzindo novos questionamentos (Favret-Saada, 1977; Rosaldo, 1988; Marques \& Villela, 2005; Biondi, 2010).

Esse perfil de trabalho de investigação vem sendo debatido na recente produção em antropologia da educação, no Brasil (Gusmão, 1997; Dauster, 2004, 2012; Oliveira, Boin \& Búrigo, 2018; Oliveira, 2015; Rosistolato, 2016; Rosistolato \& Prado, 2015; Perosa, 2006). Para tanto, a antropologia pode ser entendida como uma maneira de oferecer chaves interpretativas da vida social em espaços e através de experiências educacionais, nos mais diferentes cenários de interações - famílias e alunos(as) entre si (Willis, 1977; Ferguson, 2001), vizinhos (Lahire, 2004), alunos(as) e professores(as) (Borges, 2016), famílias, membros da administração escolar e do planejamento educacional (Lareau, 2003; Gomes, 2018).

Essas perspectivas valorizam a construção de possibilidades teóricas e conceituais para perceber e analisar as condições em que o ensino ocorre, aproveitando as surpresas das relações entre o(a) professor(a) e os(as) alunos(as), não só como turma, mas também indivíduos em sala de aula. Seus valores morais sustentam códigos de conduta, alianças, amizades e inimizades, que podem passar por reavaliações, interpostas por frases como: 'eu nunca tinha pensado nisso', ou 'por esse caminho', ou 'entendido dessa maneira, ouvidas por mim durantes as horas lecionadas de LECS.

\section{Os outros que importam}

Como os(as) alunos(as) falam de si e dos galos de briga? A ênfase das suas falas estava no processo de preparação e não na disputa em si: nas regras ali estabelecidas, se havia descanso para os galos, por exemplo, ou se eram portadores de quais tipos de artefatos para ferimento do oponente, colocados em suas pernas. Afinal, meu interesse não era construir uma interpretação coletiva com a turma sobre briga de galos e nem desenvolver um projeto de pesquisa a partir disso. Nesse sentido, vale registrar 
que não houve informação alguma sobre uma sistematização na região das técnicas e demais conhecimentos sobre as brigas de galos, em manuais, por exemplo, ou qualquer tipo de literatura especializada envolvendo quaisquer dos participantes, fossem livros ou revistas, ao contrário do que Teixeira (1997) observou no Rio Grande do Sul, bem como McCaghy e Neal (1994:68) na cidade de Nova York e noutras dos EUA.

Segundo as conversas em sala de aula, avalio que não foi estabelecida uma relação de simbiose, no sentido colocado por Tsing (2015), entre os(as) alunos(as) e os galos e nem que eles(as) tenham revelado essa perspectiva nas intervenções sobre as minúcias da preparação desses animais para as disputas, assim como dos agentes envolvidos, tratados como portadores de expertise, no sentido de Collins e Evans (2010). Não se trata, assim, de uma relação de companheirismo com os animais, ao contrário de experiências etnográficas vividas por Tsing e os produtores de cogumelo, em diferentes lugares. No caso aqui analisado, as pessoas contaram suas histórias através do entendimento de sua relação, metafórica no caso, com a briga de galos, em comparação com o que entenderam da experiência de Geertz, vista como pouco consistente na medida em que não teria compreendido pontos centrais em jogo.

Os(as) alunos(as) fizeram uma primeira leitura mais colada ao que Cassirer (1997) chama por "sentido universalista da história", isto é, a partir do entendimento de que certas situações são vividas em qualquer parte do mundo, de forma semelhante, deixando clara a possibilidade de comparações mais diretas entre tais experiências. Tal concepção, base da ideia iluminista de história e historiografia como progresso, em alguma medida, remete a características presentes na concepção de história de antropólogos da segunda metade do século XIX, tradicionalmente caracterizados como membros do evolucionismo cultural (Bowler, 2003; Stocking Jr., 2001).

Busquei ser coerente com a estratégia pedagógica adotada e não podar tais comentários ocorridos no primeiro contato dos(as) estudantes com o texto. Eles(as) ainda não haviam compreendido que há diferenças entre as relações sociais onde moram e onde Geertz pesquisou, o que em alguma medida era esperado por mim, tendo preparado uma explicação sobre o que chamei por diferenças culturais. Retornei às ideias sobre natureza e cultura para explicar que há formas de se entender a historiografia dos animais, bem como da relação entre suas mais diversas espécies e os seres humanos.

Existem linhas interpretativas que opõem ou não as concepções de natureza e cultura, com maior ou menor ênfase, na agência dos animais como questionamento da suposta superioridade da espécie humana sobre as demais (Osório, 2015). A ideia presente na narrativa dos(as) alunos(as) foi a de domesticação, tanto no sentido do entendimento de Lévi-Strauss (1997), sobre a construção de classificações intelectuais que fazemos das espécies por meio de experiências socialmente compartilhadas, quanto no de controle humano de outras espécies. Nas explicações dos(as) alunos(as) acerca de suas conquistas pessoais, não havia lugar para presença transformadora de qualquer outra espécie - pensando nos termos de Tsing (2015). O mesmo se pode afirmar sobre os sentidos conferidos às frustrações com familiares, vizinhos e amigos.

O que apareceu de maneira marcante nas falas dos(as) alunos(as) foi que "amam estudar e ensinar, e não trabalhar na lavoura”, sendo estes os verbos usados para referenciar cada uma dessas atividades. Disseram que seus familiares mostram orgulho de trabalhar nas fazendas e dos sacrificantes 
resultados obtidos para suas famílias, mas recheiam as histórias, inclusive as das brigas de galos, com tramas sinistras de ameaças e assassinatos, em disputas ocorridas entre eles e os patróes associados a capangas ou entre as famílias do patronato. Tais relatos presentes remontam agudas semelhanças com as pesquisas de Sigaud (2004), porque contém discursos que podem ser lidos sob as lentes do que Bourdieu (1996) chamou por "economia linguística”. Revelam parte dos estoques de expressão verbal disponíveis e usados pelos falantes a partir de diferentes autorizações sociais, de acordo com as relações de poder em jogo entre os que participam das interlocuções verbais.

As famílias ligadas à história que os(as) alunos(as) narraram envolvendo a disputa de terras resolvida através de uma briga de galos não são reconhecidas nas falas em sala de aula como pessoas que gostam dos elementos da natureza. São descritas como gente que não se preocupa com qualquer outra maneira de se relacionar com a terra, as plantações, que não seja predatória, lucrativa. O mesmo ocorre em relação às pessoas que há gerações trabalham nessas fazendas, familiares dos(as) alunos(as). Ou seja, trata-se de um lugar em que as relações são historicamente baseadas em lucrativas dominações permanentes de latifundiários, sobre pessoas que têm pouca possibilidade de exercer outro trabalho remunerado e melhorar de vida, em termos de acesso a condições mais adequadas de existência material, com forte reverberação na afetividade, além de precário acesso a mediações jurídicas (Sigaud, 1996).

Em certa medida, o cenário pesquisado por Sigaud e o que apareceu nas falas dos alunos em Codó conformam semelhanças com as estratégias de disputas familiares analisadas por Marques (2002), em processos de longa duração estrutural, no sentido de Sahlins (1995), de relações peculiares com as possibilidades de acesso ao universo jurídico e as justificativas morais para manobras dos meios judiciais oficiais. Não tenho intenção de investigar, ao menos aqui nesse artigo, como essas querelas locais entre famílias reconhecidamente monopolistas dos poderes político, econômico e administrativo público se fazem presentes nas formas narrativas de moradores de Codó e cercanias, membros ou não daqueles coletivos. $\mathrm{Na}$ ausência de estudos específicos sobre tais conflitos para a região onde esse município se encontra, ao trazer à tona o que Marques (2002) e Villela (2004) tratam por "questão", como uma categoria nativa, minha ideia é fornecer elementos, mesmo que fragmentários, para a compreensão de dados que apareceram de maneira marcante nas falas dos alunos. O mesmo ocorre para as relações que imaginam terem sido de escravização de africanos, indígenas e seus descendentes mais próximos.

Dado esse contexto, não haveria motivos para os galos serem tratados de forma distinta e para que não fossem usados como espécie de avatar por membros de elites locais, ao serem preparados e postos para brigar, a fim de decidirem sobre limites de terras, na ausência de uma justiça ou de leis fundiárias eficientes ou de amplo alcance. Talvez ajude na compreensão desse cenário o fato de que nessa região do Maranhão, tais elites latifundiárias foram conformadas pela exploração do trabalho de africanos escravizados, coletivos indígenas e seus descendentes. O crescimento de Codó e cercanias, em termos populacionais e econômicos, ocorreu no âmbito dos investimentos anglo-portugueses na produção de algodão, para as fábricas de tecidos de Londres e Manchester, na segunda metade do século XVIII. Conforme demonstrei em artigo ainda inédito com da Silva (Silva \& Couceiro, 2021, no prelo), esse quadro está ligado ao inédito aumento de importação de africanos escravizados para o Maranhão, fundamentalmente para as regiões produtoras de algodão, em razão de suas condições ambientais. 
Tal situação gerou conflitos entre os senhores, seus prepostos e essas populações, que se reuniram em coletivos de fugitivos, formando a base dos assim chamados remanescentes de quilombolas, ao que Gomes $(2005 ; 2008)$ denominou "proto-campesinato maranhense" ou "campo negro". Esse fenômeno também foi estudado por Assunção (2015), como parte do que seriam os antecedentes das lutas separatistas durante o Império, culminando na Balaiada (1838-41). Referências a tramas desse processo podem ser detectadas em depoimentos orais, presentes no que moradores dessas localidades entendem sobre como teriam ocorrido as relações entre senhores, seus prepostos e os escravizados, conforme demonstrou Assunção (2008). Não cabe aqui investigar a fundo os critérios e as condições de possibilidades para tais formulações narrativas, mas sim apenas apontar sua presença em termos de chave-interpretativa dos dados que venho apresentando.

Esses elementos abrem a possibilidade para compreender parte dos entendimentos dos(as) alunos(as) sobre o texto de Geertz, na medida em que os referidos latifundiários se relacionavam com os galos para briga como subespécie em relação à sua, posto assim já se relacionarem com os(as) demais moradores(as) locais, considerando-os(as) outra subespécie. Codó e cercanias se encaixam no perfil de lugares estudados por Wolf (1969) e Mintz (Wolf \& Mintz, 2010), marcados pela violência das plantations, matriz comportamental dos latifundiários que subjugam outros coletivos por anos, em trabalhos mal remunerados e em péssimas condições de segurança e saúde em suas fazendas. Faz parte do costume dos latifundiários se relacionarem no mesmo patamar de superioridade com o meio ambiente e demais pessoas que não vejam por semelhantes nas relações de poder.

As falas dos(as) alunos(as) sobre conseguirem quebrar esse destino social de subjugamento através dos estudos carregavam "orgulho" e "dor", palavras por eles usadas, em situações dramáticas, no sentido de Turner (1975). Viviam uma conjuntura em que a educação formal foi por eles(as) agenciada como meio para alterar algum tipo de herança relativa ao letramento, em sua ausência ou precariedade (Bourdieu, 2012). Contaram sofrer acusações de parentes, em alguns casos dos(as) próprios(as) cônjuges e também de vizinhos(as), envolvendo questões de honra e desonra relativas à volta aos estudos.

Primeiro, todos(as) as(os) alunos(as) afirmaram que tiveram de gerir o tempo dos afazeres do lar e dos cuidados com os(as) parentes de modo mais dinâmico, para que pudessem se dedicar às leituras e à escrita dos trabalhos. Pelo mesmo motivo, disseram que ficavam menos tempo em festas ou cultos religiosos, assim como "jogando conversa fora" com os(as) vizinhos(as) e amigos(as) da cidade. Segundo eles(as), essas pessoas sentiram-se rejeitadas, como que trocadas, por alguma coisa que era importante para os(as) alunos(as), mas que não identificavam efeito positivo algum nas suas vidas. Assim, os(as) estudantes eram acusados(as) de serem egoístas e de achar que teriam passado a um patamar de superioridade na hierarquia social.

Tais relatos ajudam a visualizar os caminhos pelos quais os(as) próprios(as) alunos(as) identificaram e deram sentido aos termos usados na capacidade de significação da sua forma de existência, ou seja, em que medida o avanço nas chances escolares objetivas exprime-se no campo das percepções cotidianas (Bourdieu \& Passeron, 2009). Tais significados, segundo os relatos, eram inicialmente compartilhados por familiares e vizinhos, mas foram paulatinamente entrando em conflito com os novos elementos adquiridos pelos(as) discentes, nas experiências universitárias. 
As apropriações que os(as) estudantes fazem de leituras e de toda a carga de situações pertinentes ao universo institucional de ensino trazem abalos nas relações, modificando-as em vários termos, ajudando o(a) pesquisador(a) a mapear as desigualdades sociais mais estruturadas (Lareau, 2015). Um novo mapa de significação estava em construção, segundo percebi, pelos(as) alunos(as) de LECS, por meio da universidade como algo por eles(as) vivido intensamente, mas não necessariamente compartilhado pelas pessoas com as quais lidavam nos seus universos rotineiros.

Nesse sentido, situações ora compartilhadas passam a ter novos entendimentos e questionamentos por parte dos(as) alunos(as), numa perspectiva distinta da de seus familiares e amigos(as). Por meio das aulas, os(as) alunos(as) estavam se expressando cada vez mais numa linguagem pouco compreendida por essas pessoas, que os(as) encaravam como sendo novos(as) especialistas em assuntos ligados à educação escolar em geral, bem como acerca do que ocorre dentro e a partir das escolas, incluindo as regras burocráticas envolventes.

\section{Conclusões}

As interpretações produzidas pelos(as) estudantes sobre os fragmentos de textos de certos antropólogos e de minha narrativa sobre algumas de suas teorias, conceitos e breves passagens biográficas trouxeram para seus olhares o que seria antropologia em termos gerais e como ela pode oferecer variações no repertório de questionamentos e respostas às perguntas por eles(as) propostas. Os(as) alunos(as) perceberam a possível importância da antropologia na medida em que foram se vendo nas discussões, adaptando livremente, num primeiro contato, situações de suas vidas com o que lhes estava sendo apresentado. Seus entendimentos iniciais dos conteúdos puderam ser refinados na medida em que observei a oportunidade de adentrar um mundo completamente desconhecido para mim, porém, extremamente familiar aos/às alunos(as).

A briga de galos, como ensinou Geertz (2000), pode ser a chave de entrada para encontrar outros sentidos da dinâmica da vida social, seus paradoxos morais, no que o autor chama de "rede de significados". Minhas análises em momento algum buscaram seguir os predicados que o autor estabeleceu no famoso texto e no conjunto dos artigos do livro do qual faz parte, em certa medida, como um estilo de fazer antropologia por ele batizada de hermenêutica (Handler, 1991; Hirsch \& Wright, 1993; Smith, 2011). Além do mais, eu não teria estofo de leituras e formação em filosofia da linguagem para tal empreitada, nos moldes realizados por Geertz.

Assim, as narrativas desenvolvidas nesse artigo foram constituídas no âmbito das relações estabelecidas entre o professor, também pesquisador, em sala de aula como campo, com os(as) alunos(as) como interlocutores(as). Nas aulas, busquei operar segundo a problematização dos jogos de interesses dos(as) alunos(as) com os meus, assim como das devidas construções conceituais, para dar conta de questionamentos dos(as) antropólogos(as) acerca da suposta neutralidade político-científico em campo, de suas escolhas éticas e de estilo narrativo na apresentação de dados e análises (Clifford \& Marcus, 1986; Tsing, 1993). 
As brigas de galos não eram fatos singulares na vida dos(as) alunos(as), mas sim rotineiros há duas ou três gerações. Porém, não as encarei como sendo algo ligado ao senso comum, porque as narrativas dos(as) alunos(as) traziam informações que mostravam o quão esse evento marcava suas percepções acerca das instigantes relações com e entre as pessoas envolvidas, sob interesses ora semelhantes, ora distintos. Procurei valorizar as primeiras impressões e leituras $\operatorname{dos}($ as $)$ discentes sobre antropologia, fixando meu olhar naquilo que havia lhes chamado atenção no artigo de Geertz.

A ideia foi lecionar a partir das apreensões dos(as) alunos(as), incentivando as conexões com suas próprias experiências, ou seja, que eles(as) mesmos pudessem se apoderar do que estava sendo ensinado como algo que lhes fizesse sentido, num exercício de permanente identificação. Em um segundo momento, coube a mim, como professor, realizar a passagem dessa leitura mais livre, noivando com o senso comum, para análises melhor informadas pelas teorias e pelos conceitos da antropologia.

Luiz A. Couceiro é Doutor em Ciências Humanas (Antropologia Cultural) pela Universidade Federal do Rio de Janeiro (UFRJ), com pós-doutorado em Antropologia Social no Museu Nacional (UFRJ) e no Fernand Braudel Center - State University of New York at Binghamton University (SUNY-BU), sendo Professor Associado 1 no Departamento de Sociologia e Antropologia da UFMA.

Esse artigo contou com auxilio da Coordenação de Aperfeiçoamento de Pessoal de Nivel Superior (Capes) para a realização das aulas no Parfor e com bolsa da Fundação de Amparo à Pesquisa e ao Desenvolvimento Cientifico e Tecnológico do Maranhão (Fapema), Edital n. 006/2019 - Pós-Doutorado no Exterior, durante sua redação.

\section{REFERÊNCIAS}

Abu-Lughod, L. (1986). Veiled sentiments: honor and poetry in a Bedouin Society. Berkeley, Los Angeles: University of California Press.

Amit, V. (ed). (2000). Construct the field: ethnographic fieldwork in the contemporary world. London, New York: Routledge.

Assunção, M. R. (2008). A guerra dos Bem-te-vis: a Balaiada na memória oral. São Luís: EdUFMA.

Assunção, M. R. (2015). De caboclos a bem-te-vis. Formação do campesinato numa sociedade escravista: Maranhão, 1800-1850. São Paulo: Annablume. 
Biondi, K. (2010). Junto e misturado: uma etnografia do PCC. São Paulo: Editora Terceiro Nome.

Boas, F. (2004a). Raça e progresso. In C. Castro (org). Franz Boas: Antropologia Cultural (pp. 6786). Rio de Janeiro: Jorge Zahar.

Boas, F. (2004b). Antropologia. In G. W. Stocking Jr. (org). A formação da antropologia americana (1883-1911): Antologia/Franz Boas (pp. 323-340). Rio de Janeiro: Contraponto, Editora UFRJ.

Borges, A. (2016). República das mangas ou sobre o amargo gosto de tudo o que amadurece à força. Revista Pós Ciências Sociais, 13(25), 21-42. https://doi.org/10.18764/2236-9473.v13n25p21-42

Bourdieu, P. (1996). Economia das trocas linguisticas: o que falar quer dizer. São Paulo: EdUSP.

Bourdieu, P. (2012). As contradições da herança. In M. A. Nogueira, \& A. Catani. Escritos de educação (pp. 229-237). 13ª ed. Petrópolis: Vozes.

Bourdieu, P., \& Passeron, J. (2009). Los herderos: los estudiantes y la cultura. $2^{\text {a }}$ ed. Buenos Aires: Siglo Veintiuno.

Bowler, P. J. (2003). Evolution: The History of an Idea. Berkeley: University of California Press.

Caplan, P. (2003). Introduction: anthropology and ethics. In P. Caplan (ed). The Ethics of Anthropology: debates and dilemmas (pp. 1-33). New York: Routledge. https://doi.org/10.4324/9780203633670

Cassirer, E. (1997). A filosofia do Iluminismo. 3 ed. Campinas: Editora da UNICAMP.

Clifford, J., \& Marcus, G. (eds). (1986). Writing culture: the poetics and politics of ethnography. Berkley, Los Angeles, London: University of California Press. https://doi.org/10.1525/9780520946286

Collins, H., \& Evans, R. (2010). Repensando a expertise. Belo Horizonte: Fabrefactum.

Couceiro, L. A. (2017). Cabra marcado para Bourdieu: educação e narrativas de sofrimento e violência na experiência escolar. Horizontes Antropológicos, 49, 287-309. https://doi.org/10.1590/s010471832017000300011

Couceiro, L. A. (2020). Etnografia hiper-realista: uma proposta para interpretar processos de ensino e aprendizagem. Revista Contemporânea de Educação, 15(32), 7-25. https://doi.org/10.20500/rce. v15i32.31554

Crapanzano, V. (1980). Tuhami: a portrait of a Moroccan. Chicago, London: University of Chicago Press. https://doi.org/10.7208/chicago/9780226191461.001.0001 
Crapanzano, V. (1986). Herme's dilema: the masking of subversion in ethnographic description.” In J. Clifford, \& G. Marcus (ed.). Writing culture: the poetics and politics of ethnography (pp. 51-76). Berkley, Los Angeles, London: University of California Press. https://doi.org/10.1525/9780520946286-005

Dauster, T. (2004). Entre a antropologia e a educação: a produção de um diálogo imprescindível e de um conhecimento híbrido. Ilha, 6(1-2), 197-207. https://periodicos.ufsc.br/index.php/ilha/article/ view/16610

Dauster, T. (org). (2012). Etnografia e Educação. Rio de Janeiro: Lamparina.

Evans-Pritchard, E. E. (1931). Sourcery and native opinion Africa: Journal of the Africa International Institute, 4(1), 22-55. https://doi.org/10.2307/1155736

Fabian, J. (1971). On professional ethics and epistemological foundations. Current Anthropology, 12(2), 230-232. https://doi.org/10.1086/201197

Fabian, J. (2012). Cultural anthropology and the question of knowledge. Journal of the Royal Anthropological Institute, 18(2), 439-453. https://doi.org/10.1111/j.1467-9655.2012.01751.x

Favret-Saada, J. (1977). Les Mots, La Mort, Les Sorts. Paris: Gallimard.

Ferguson, A. A. (2001). Bad Boys: public schools in the making of black masculinity. Michigan: The University of Michigan Press. https://doi.org/10.3998/mpub.16801

Firth, R. (ed). (1957). Man and culture: an evaluation of the work of Bronislaw Malinowski. New York: Humanities Press.

Fonseca, C. (2008). A interpretação das culturas: festejando os 35 anos. Cadernos de Campo, 16(16), 281-286. https://doi.org/10.11606/issn.2316-9133.v16i16p281-286

Foote Whyte, W. (2005). Sociedade de esquina: a estrutura social de uma área urbana pobre e degradada. Rio de Janeiro: Jorge Zahar.

Geertz, C. (1995). After the fact: two countries, four decades, one anthropologist. Cambridge, London: Harvard University Press.

Geertz, C. (2000). Deep play: notes on the Balinese Cockfight. In The interpretation of cultures (pp. 412-453). New York: Basic Books. https://doi.org/10.1007/978-1-349-62397-6_10

Gluckman, M. (1987). Análise de uma situação social na Zululândia moderna. In B. Feldman-Bianco (org.). Antropologia das sociedades contemporâneas (pp. 227-344). São Paulo: Global. 
Gomes, F. dos S. (2005). A hidra e os pântanos: mocambos, quilombos e comunidades de fugitivos no Brasil - séculos XVII-XIX. São Paulo: Editora UNESP, Editora Polis.

Gomes, F. dos S. (2008). Peasants, maroons, and the frontiers of liberation in Maranhão. Review (Fernand Braudel Center), 31(3), 373-399.

Gomes, R. F. R. (2018). Ainda somos os mesmos e estudamos como nossos pais. Curitiba: Appris.

Gusmão, N. (1997). Antropologia e educação: origens de um diálogo. Cadernos Cedes, 18(43), 8-25. https://doi.org/10.1590/S0101-32621997000200002

Handler, R. (1991). An interview with Clifford Geertz. Current Anthropology, 32(5), 603-613. https://doi.org/10.1086/204008

Hirsch, S. M., \& Wright, P. G. (1993). De Bali al posmodernismo: una entrevista con Clifford Geertz. Alteridades, 3(5), 119-126.

Hume, L., \& Mulcock, J. (eds). (2004). Anthropologists in the field: cases in participant observation. New York: Columbia University Press.

Lahire, B. (2004). Sucesso escolar nos meios populares: as razões do improvável. São Paulo: Ática.

Lareau, A. (2003). Unequal Childhoods: Class, Race, and Family Life. Berkeley: University of California Press.

Lareau, A. (2015). Cultural Knowledge and Social Inequality. American Sociological Review, 80(1), 1-27. https://doi.org/10.1177/0003122414565814

Leach, E. R. (1996). Sistemas politicos da Alta Birmânia: um estudo da estrutura social Kachin. São Paulo: Edusp.

Lévi-Strauss, C. (1976). Totemismo hoje. In Lévi-Strauss (pp. 95-187). Coleção Os Pensadores, vol. L. São Paulo: Abril Cultural.

Lévi-Strauss, C. (1997). O pensamento selvagem. $2^{\text {a }}$ ed. Campinas: Papirus.

Malinowski, B. (1935). Part VI. An ethnographic theory of the magical word. In Coral Gardens and their magic (pp. 213-248). v. II. London: Georde Allen and Unwin Ltd.

Malinowski, B. (1984). Argonautas do Pacifico Ocidental: um relato do empreendimento e da aventura dos nativos nos arquipélagos da Nova Guiné melanésia. $3^{\mathrm{a}}$ ed. São Paulo: Abril Cultural.

Marques, A. C. (2002). Intrigas e questões: vingança de família e tramas sociais no sertão de Pernambuco. Rio de Janeiro: Relume-Dumará. 
Marques, A. C., \& Villela, J. M. (2005). O que se diz, o que se escreve: etnografia e trabalho de campo no sertão de Pernambuco. Revista de Antropologia, 48(1), 37-74. https://doi.org/10.1590/ S0034-77012005000100002

Mccaghy, C. H., \& Neal, A. G. (1994). The fraternity of cockfighters: ethical embellishments of an illegal sport. In A. Dundes (ed). The cockfight: a casebook (pp. 66-80). Madison: The University of Wisconsin Press.

Mintz, S. W. (1984). Encontrando Taso, me descobrindo. Dados Revista de Ciências Sociais, 27(1), 45-58.

Oliveira, A. (2015). Sobre o Lugar da Educação na Antropologia Brasileira. Temas em Educação, 24(1), 40-50.

Oliveira, A., Boin, F., \& Búrigo, B. (2018). Quem tem medo de etnografia? Revista Contemporânea de Educação, 13(26), 10-30. https://doi.org/10.20500/rce.v13i26.12243

Ortner, S. (2007). Uma atualização da teoria prática; Poder e projetos: reflexões sobre a agência. In M. Grossi, P. Fry, \& C. Eckert (orgs). Conferências e diálogos: saberes e práticas antropológicas (pp. 1944; 45-80). Blumenau: Nova Letra.

Osório, A. (2015). Entre o real e o representado: um debate na história dos animais. Caderno Eletrônico de Ciências Sociais, 3(1), 75-94. https://doi.org/10.24305/cadecs.v3i1.12275

Perosa, G. S. (2006). Aprendizagem das diferenças sociais: classe, gênero e corpo em uma escola para meninas. Cadernos Pagu, 26, 87-111. https://doi.org/10.1590/S0104-83332006000100005

Radcliffe-Brown, A. R. (1922). The Andaman Islanders: a study in social anthropology. London: Cambridge University Press.

Radcliffe-Brown, A. R. (1978). O método comparativo em Antropologia Social. In J. C. Melatti (org). Radcliffe-Brown (pp. 43-58). São Paulo: Ática.

Rapport, N. (1997). Edifying anthropology: culture as conversation; representation as conversation. In A. Ames, J. Hockey, \& A. Dawson (eds). After writing culture: epistemology and praxis in contemporary anthropology (pp. 177-191). London, New York: Routledge. https://doi. org/10.4324/9780203450987_chapter_11

Rosaldo, R. (1988). Ideology, place, and people without culture. Cultural Anthropology, 3(1), 77-87. https://doi.org/10.1525/can.1988.3.1.02a00070 
Rosistolato, R. (2016). “Você sabe como é, eles não estão acostumados com antropólogos!": uma análise etnográfica da formação de professores.” Pro-Posições, 24(2), 41-54. https://doi.org/10.1590/ S0103-73072013000200004

Rosistolato, R., \& Prado, A. P. do. (2015). Etnografia em pesquisas educacionais: o treinamento do olhar. Linhas Criticas, 21(44), 57-75.

Sahlins, M. (1995). Historical metaphors and mythical realities: structure in the early history of the Sandwich Islands Kingdom. Michigan: The University of Michigan Press.

Sigaud, L. (1996). Direito e coerção moral no mundo dos engenhos. Estudos Históricos, 18, 361-388.

Sigaud, L. (2004). Armadilhas da honra e do perdão: usos sociais do direito na mata pernambucana. Mana (10)1, 131-163. https://doi.org/10.1590/S0104-93132004000100005

Silva, R. V. C. da, \& Couceiro, L. A. (2021). One Possible Analysis of How Quilombos Arose in Maranhão, Brazil (1780-1820) in the Face of the World Economy. No prelo.

Singer, A., \& Street, B. V. (eds). (1972). Zande themes: essays presented to Sir Edward Evans-Pritchard. Oxford: Basil Blackwell.

Smith, Philip. (2011). The Balinese Cockfight Decoded: Reflections on Geertz and Structuralism. In J. C. Alexander, P. Smith, \& M. Norton. Interpreting Clifford Geertz: cultural investigation in Social Sciences (pp. 17-32). New York: Palgrave Macmillan. https://doi.org/10.1057/9780230118980_3

Stocking Jr., G. W. (1983). The ethnographer's magic: fieldwork in British Anthropology from Tylor to Malinowski. In Observers observed: essays on ethnographic fieldwork (pp. 70-120). Wisconsin: The University of Wisconsin Press.

Swidler, A. (1996). Geertz's ambiguous legacy: review of “The interpretation of Cultures" by Clifford Geertz." Contemporary Sociology, 25(3), 299-302. https://doi.org/10.2307/2077435

Teixeira, S. A. (1997). O simbolismo essencial das brigas de galos. Horizontes Antropológicos, 6, 223 280. https://doi.org/10.1590/s0104-71831997000200013

Thornton, R. (1985). “Imagine yourself set down...”: Mach, Frazer, Conrad, Malinowski and the role of imagination in ethnography. Anthropology Today, 1(5), 7-14. https://doi.org/10.2307/3032822

Tsing, A. L. (1993). In the realm of the Diamond Queen: marginality in an out-of-the-way place. Princeton: Princeton University Press.

Tsing, A. (2015). The mushroom at the end of the world: on the possibility of life in the capitalism ruins. Princeton, Oxford: Princeton University Press. https://doi.org/10.1515/9781400873548 
Turner, V. W. (1975). Dramas, Fields, and Metaphors: Symbolic Action in Human Society. Ithaca: Cornell University Press.

Villela, J. L. M. (2004). O Povo em armas: violência e política no sertão de Pernambuco. Rio de Janeiro: Relume Dumará.

Willis, P. (1977). Learning to Labor: How Working Class Kids Get Working Class Jobs. New York: Columbia University Press.

Wolf, E. (1969). Peasant Wars of the Twentieth Century. New York: Harper \& Row.

Wolf, E. R., \& Mintz, S. W. (2010). Fazendas e plantações na Meso-América e nas Antilhas. In S. W. Mintz O poder amargo do açúcar: produtores escravizados, consumidores proletarizados (pp. 169-223). $2^{a}$ ed. Recife: Editora Universitária UFPE. 


\title{
BRIGA DE GALOS NO MARANHÃo: DIDÁtiCAS ATRAVÉS DE APROPRIAÇÕES DE TEXTOS DE ANTROPOLOGIA
}

Resumo: Entre julho de 2014 e janeiro de 2015, lecionei Laboratório de Ensino de Ciências Sociais no município de Codó (MA), pelo Programa de Formação de Professores para Educação Básica (Profebpar) existente na Universidade Federal do Maranhão. Ao saberem que era antropólogo, contudo, os alunos pediram que fizesse um "resumo de antropologia", pois alegavam que não "haviam entendido" essa disciplina. De improviso, como estratégia pedagógica, abordei processos de construção de classificação social através de discussões entre natureza e cultura, costurando vários autores-exemplares de tipos de antropologia. Os alunos riram das interpretações de Clifford Geertz sobre briga de galos, e foi quando descobri que eram familiarizados com esse universo. Nesse texto, analiso qual foi o lugar das experiências dos alunos nas suas leituras pragmáticas dos textos, influenciando as dinâmicas de ensino-aprendizagem de antropologia.

Palavras-chave: ensino de Antropologia; etnografia; metodologia do ensino; formação docente; processo de ensino-aprendizagem.

\section{COCKFIGHTING IN MARANHÃO: DIDATICS THROUGH APPROPRIATIONS OF ANTHROPOLOGY PUBLICATIONS}

\begin{abstract}
Between July 2014 and January 2015, I taught a course called Social Sciences Teaching Laboratory, in the city of Codó, Maranhão State, Brazil, by Teacher Training Program for Secondary Education, existing in Federal University of Maranhão State. Upon learning that I was an anthropologist, however, the students asked me to do an "anthropology summary", as they claimed that they had not "understood" this discipline. As a pedagogical strategy, I approached, by improvised, processes of construction of social classification through discussions between nature and culture, sewing several exemplary authors of styles of anthropology. The students laughed at Clifford Geertz's interpretations of cockfighting, and that's when I discovered that they were familiar with this universe. In this text, I analyze the place of the students' experiences in their pragmatic readings of the texts, influencing the teaching-learning dynamics of anthropology.
\end{abstract}

Keywords: Anthropology teaching; ethnography; Teaching methodology; teacher education; teaching-learning process.

RECEBIDO: $08 / 04 / 2020$

ACEITO: 08/01/2021 